\title{
Study of the Aging of a Concrete Reinforced by Alkali Resistant Glass Fiber in the Wet Environment
}

\author{
Mohammed-Amin Boumehraz ${ }^{1,2^{*}}$, Mekki Mellas ${ }^{1,2}$, Kamel Goudjil $^{3}$, Farida Boucetta ${ }^{4}$ \\ ${ }^{1}$ Laboratory of Research in Civil Engineering (LRCE), University of Biskra, BP 145 RP, Biskra 07000, Algeria \\ ${ }^{2}$ Department of Civil Engineering, University of Biskra, BP 145 RP, Biskra 07000, Algeria \\ ${ }^{3}$ Laboratory of Civil Engineering and Environment (LCEE), University of Jijel, Jijel 18000, Algeria \\ ${ }^{4}$ Laboratory of Physics of Thin Films and Applications, University of Biskra, BP 145 RP, Biskra 07000, Algeria
}

Corresponding Author Email: amine18gc@yahoo.com

https://doi.org/10.18280/acsm.440202

Received: 13 December 2019

Accepted: 10 February 2020

\section{Keywords:}

aging, sulfate resistant cement (SRC), ARHP

glass fiber, durability, concrete

\begin{abstract}
The Glass fiber reinforced concrete (GFRC) is a composite material; it is regarded as a suitable material for concrete structures. The GFRC is reinforced with alkali resistant (AR) glass fibers, this type of glass fibers understands from 15 to $20 \%$ of the zirconium mass; this addition improves considerably the durability of glass in the alkaline environments, but does not solve entirely the problems of its degradation. Generally, the rate of aging of the composite cement-glass depends on type of glass fiber used and condition of the environment. The objective of this paper is to study the effect of glass fibers on the compressive and flexural strength of a cement concrete (sulfate resistant cement) SRC reinforced by alkali-resistant high performance (ARHP) glass fibers and immersed in a wet medium. The results obtained in this study showed that the compressive strength and flexural strength of GFRC depend on the percentage of glass fibers and the exposure time of specimen in the wet medium. The optimal percentage of glass fibers is $3 \%$ for both strengths. More still, percentage of $5 \%$ of glass fibers influence negatively on the mechanical characteristics of the concrete fiber. In addition, the use of SRC cement with additions of $3 \%$ of silica fume and $20 \%$ of the slag can decrease the porosity of the concrete fiber and improve the durability of the concrete fiber.
\end{abstract}

\section{INTRODUCTION}

The first commercial production of glass fibers was in 1936 [1]. These fibers are generally found in the form of the very fine filaments (simple, braided, woven...) with diameters of 2 $\mathrm{X} 10^{-6}$ to $13 \times 10^{-6} \mathrm{~m}$ [2]. The glass fibers reinforced concrete (GFRC) was recognized by the Russians at 1940 [3, 4]. The two principal components of the GFRC are the glass fiber and the cementing matrix [5]. Recently, the GFRC was regarded as a suitable material for concrete structures, and it can be used with reinforcing steel as reinforcement. Moreover, $90 \%$ of glass fibers in the world are manufactured starting from glass E $[6,7]$. Unfortunately, its physical and chemical properties do not meet the requirements of modern technology, because this type of glass involves a reduction of resistance. This is due to the reactivity to alkalis in the paste of hydrated cement. However, currently the glass fibers resistant to the alkalis glass (AR) are commonly used to this end [4, 7]. Alkali resistant glass fibers understands from 15 to $20 \%$ of the zirconium $\left(\mathrm{ZrO}_{2}\right)$ mass, this quantity of $\left(\mathrm{ZrO}_{2}\right)$ improves considerably the durability of glass in the alkaline environments, but does not solve entirely the problems of degradation $[6,7]$.

The durability of the GFRC depends on the properties of glass fibers which are the proportions of the mixture, the implementation, the method of compaction and hardening [8]. Usually, the optimal cementing matrix contains 2 to $4 \%$ of glass fibers to the volume of concrete, with length between 6 and $40 \mathrm{~mm}$. The rate of aging of the composites cement-glass depends on type of glass fiber used and condition of the external environment or whether [9]. Generally, the glass fibers cut is added in second stages of fresh concrete with a speed of weak relaxation to obtain a maximum workability, facility of their dispersion in the volume and limited the damage to surfaces of fibers [10]. Butler et al. in 2010 were concluded that the loss of performance and the accelerated aging of the cementing interface matrix fiber depend mainly on alkalinity of the cement matrix and the formation of portlandite on the surface of filaments [11].

Enfedaque et al. in 2012 were concluded that the cycles from freezing thawing and the immersion GFRC in hot water accelerated its aging [6]. According to Arabi et al, the addition of the rate of $3 \%$ of the silica fume can improve slightly the resistance, but does not give a sufficient protection of the surface of fibers in the environment alkaline. However, by using cement with low alkalinity the quantity of the portlandite in the matrix reduces, which involves an impoverishment of the production of the ions hydroxide, and decrease the $\mathrm{pH}$ of the solution of the pores and consequently the environment can be exhausted (basic). In addition, the $\mathrm{Ca}^{2+}$ ions can be combined with the silica fume to form new calcium silicate hydrates [12, 13]. Peled et al. in 2005 were found that the replacement of cement of GFRC by $18 \%$ of the slag and $9 \%$ the auxiliary products of dimensional stability leading to the improvement of their durability for samples immersed in a hot water bath of $50^{\circ} \mathrm{C}$ during 84 days. This improvement is explained by the absence of $\mathrm{Ca}(\mathrm{OH})_{2}$ in the composite of the 
auxiliary products of dimensional stability [14]. This study has the aim of studying the durability of concrete the cement SRC reinforced with different percentages of glass fibers ARHP immersed in a wet medium.

\section{EXPERIMENTAL}

\subsection{Used materials}

\subsubsection{Cement}

Sulfate-resistant cement (SRC) (NA 443 - CEM I $52.5 \mathrm{~N}$ ES) is used in the Lafarge cements factory- Algeria. Its chemical composition according to European standards NF EN 196-2 is presented in Table 1.

Table 1. Chemical composition of the cement

\begin{tabular}{cc}
\hline Composition & Values (\%) \\
\hline $\mathrm{C}_{3} \mathrm{~S}$ & $60-72$ \\
$\mathrm{C}_{2} \mathrm{~S}$ & $3-10$ \\
$\mathrm{C}_{3} \mathrm{~A}$ & $2-4.5$ \\
$\mathrm{C}_{4} \mathrm{AF}$ & $11-15$ \\
Gypsum & 5 \\
\hline
\end{tabular}

\subsubsection{Mineral additions}

The two mineral additions used in our experimental study are the silica fume and granulated slag. The silica used is silica ultra-fine of specific surface Blaine equal to $23 \mathrm{~m}^{2} / \mathrm{g}$ and of gray color coming from company SIKA-Algiers. The granulated slag is taken from El Hadjar (Algeria), its diameter is $6,30 \mathrm{~mm}$. The chemical analyses by X-rays diffraction of the mineral additions are illustrated in Figure 1.
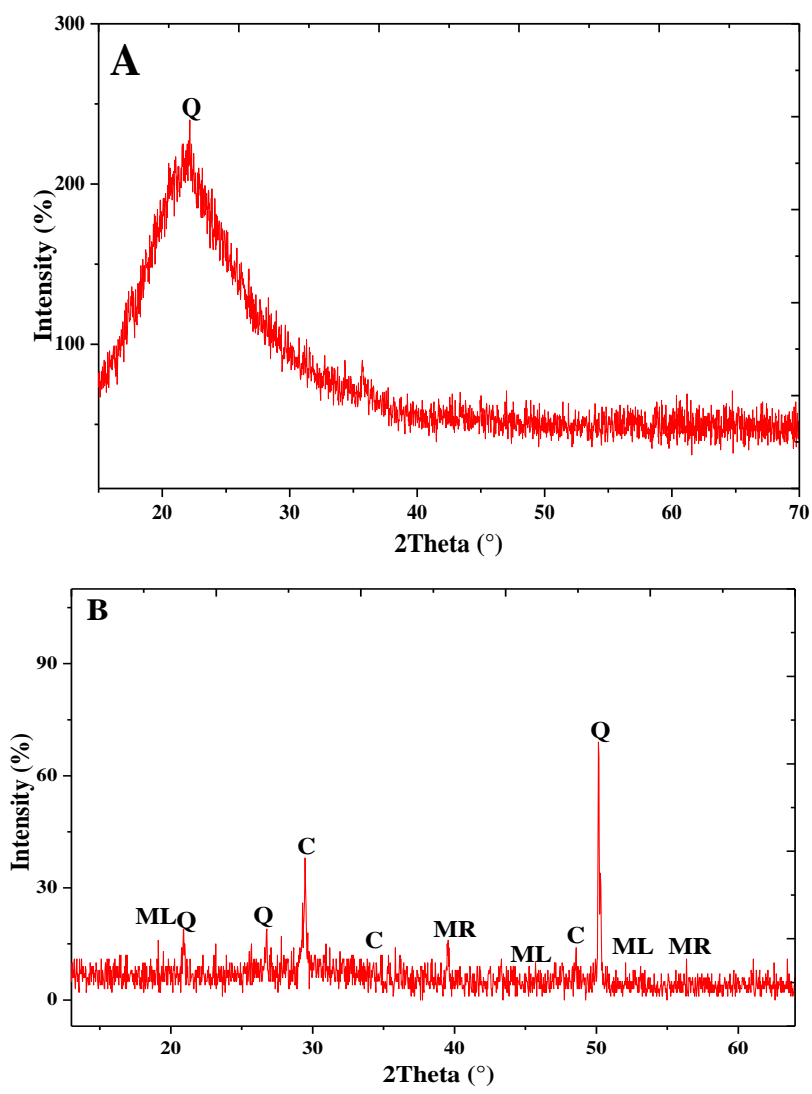

Figure 1. XRD analyses (A) Silica fume (B) Slag. (Q: Quartz, C: Calcite, ML: Melilite, MR: Merwinite)

\subsubsection{Aggregates}

Sand used is siliceous sand of a size diameter lower than 4 $\mathrm{mm}$ taken from the Oued Zehour-Algeria, its fineness modulus is about $2.54 \%$. The gravels employed are crushed and of the particle-size ranges $3 / 8 \mathrm{~mm}$ and $8 / 16 \mathrm{~mm}$, taken from the MilaAlgeria. The physical and mechanical properties of aggregates are illustrated in Table 2 .

Table 2. Physical and mechanical properties of aggregates

\begin{tabular}{cccc}
\hline & Sand & $\begin{array}{c}\text { Gravel } \\
\mathbf{3 / 8}\end{array}$ & $\begin{array}{c}\text { Gravel } \\
\mathbf{8 / 1 5}\end{array}$ \\
\hline Apparent density $\left(\mathrm{g} / \mathrm{cm}^{3}\right)$ & 1.42 & 1.39 & 1.35 \\
Absolute density $\left(\mathrm{g} / \mathrm{cm}^{3}\right)$ & 2.60 & 2.72 & 2.80 \\
Sand equivalent $(\%)$ & 77.40 & - & - \\
Properties aggregates $(\%)$ & - & 1.63 & 0.47 \\
Los Angeles coefficient $(\%)$ & - & - & 24.72 \\
Coefficient of micro deval $(\%)$ & - & - & 19.20 \\
\hline
\end{tabular}

The sand is clean with a low percentage of fines, and is perfectly suitable for ordinary concrete. Finally, these aggregates are acceptable for making ordinary concrete.

\subsubsection{Superplasticizer}

TEKSUPERFLOW $2000 \mathrm{R}$ is a super general-purpose, high plasticized reducing of water, a density of $1.18 \mathrm{pH}$ in $20^{\circ} \mathrm{C}$ $10 \pm 1$ and chloral contents of $0.10 \%$. This additive is compatible with all the types of cement, and the purpose of its added to the freshly-mixed concrete during relaxation, is to improve the handiness of the mixtures according to European standard NF EN 934-2.

\subsubsection{Alkali-resistant fiberglass}

The glass fiber used is of Cem-Wire type alkali-resistant high performance (ARHP 67/36), with a length of $36 \mathrm{~mm}$. It is characterized by its enrichment out of zirconium $\left(\mathrm{ZrO}_{2}=\right.$ $16.80 \%$ ), which confers a better durability to it with respect to the alkaline attack of cement. Chemical and mechanical properties of glass fiber ARHP given by the manufacturer Owens Corning (Spain) are presented in Table 3.

Table 3. Chemical and mechanical properties of ARHP glass fiber

\begin{tabular}{|c|c|c|c|}
\hline \multicolumn{2}{|c|}{ Chemical properties } & \multicolumn{2}{|c|}{ Mechanical properties } \\
\hline Composition & Values (\%) & Properties & Values \\
\hline $\mathrm{SiO}_{2}$ & 61.2 & Density $\left(\mathrm{Kg} / \mathrm{m}^{3}\right)$ & 2680 \\
\hline $\mathrm{Al}_{2} \mathrm{O}_{3}$ & 0.4 & Tensile tensile stress: & \\
\hline $\mathrm{B}_{2} \mathrm{O}_{3}$ & 0 & Virgin filament (MPa) & $>1 / 00$ \\
\hline $\mathrm{Na}_{2} \mathrm{O}+\mathrm{K}_{2} \mathrm{O}$ & 14.7 & Tensile modulus of & \\
\hline $\mathrm{CaO}$ & 5.6 & elasticity (MPa) & 12000 \\
\hline $\mathrm{MgO}$ & $<0.1$ & Elongation at break & \\
\hline $\mathrm{ZrO}_{2}$ & 16.8 & $(\%)$ & $3 \%$ \\
\hline $\mathrm{Fe}_{2} \mathrm{O}_{3}$ & $<0.1$ & $\begin{array}{l}\text { Coefficient of linear } \\
\text { expansion } \alpha(20 \text { and } \\
\left.100^{\circ} \mathrm{C}\right)\end{array}$ & $\begin{array}{c}7.5 \mathrm{x} \\
10^{-6}\end{array}$ \\
\hline $\mathrm{TiO}_{2}$ & $<0.1$ & Softening point $\left({ }^{\circ} \mathrm{C}\right)$ & 840 \\
\hline
\end{tabular}

\subsection{Preparation of samples and testing}

In this study, we manufacture four series of the concrete samples using the prismatic moles $(70 \times 70 \times 280) \mathrm{mm}^{3}$ and cubic $(100 \times 100 x 100) \mathrm{mm}^{3}$ in accordance with European standard NF P 18-427 and NF EN 12390-1 respectively. The samples of the concrete were mixed and hardened to $20 \pm 2{ }^{\circ} \mathrm{C}$ of temperature and relative moisture higher than $95 \%$. Table 4 
shows the various formulations of the GFRC with different percentage of fibers ARHP $(0 \%, 1 \%, 3 \%$ and $5 \%)$ and the SRC cement dosage of $400 \mathrm{Kg} / \mathrm{m}^{3}$. These specimens are preserved in a basin filled of water in 365 days duration. Measurements of compressive and flexural strength were taken according to the number of days of exposure in the humid environment $(7$, 28, 90, 180, and 365).

Each value represents the average of five measurements.

Table 4. Constituents of concrete series used

\begin{tabular}{|c|c|c|c|c|}
\hline $\begin{array}{l}\text { Composition of } \\
\text { concrete samples }\end{array}$ & $\mathbf{R O}$ & $\mathbf{R 1}$ & $\mathbf{R 3}$ & R5 \\
\hline Cement $(\mathrm{Kg})$ & 308 & 308 & 308 & 308 \\
\hline $\begin{array}{c}\text { Slag }(\mathrm{Kg})(20 \% \text { of } \\
\text { cement })\end{array}$ & 80 & 80 & 80 & 80 \\
\hline $\begin{array}{l}\text { Silica fume }(\mathrm{Kg}) \\
\text { (3\% of cement) }\end{array}$ & 12 & 12 & 12 & 12 \\
\hline Sand $(\mathrm{Kg})$ & 728.06 & 726.56 & 723.56 & 720.56 \\
\hline Gravel 3/8 (Kg) & 233.74 & 233.26 & 232.29 & 231.33 \\
\hline Gravel 8/15 (Kg) & 979.70 & 977.68 & 973.64 & 969.60 \\
\hline ARHP fiber $(\mathrm{Kg})$ & 0 & 4 & 12 & 20 \\
\hline Water (l) & 168 & 168 & 168 & 168 \\
\hline Superplasticizer (\%) & \\
\hline $\mathrm{W} / \mathrm{L}$ & \multicolumn{4}{|c|}{0.42} \\
\hline $\mathrm{S} / \mathrm{G}$ & \multicolumn{4}{|c|}{0.6} \\
\hline
\end{tabular}

\section{RESULTS AND INTERPRETATIONS}

\subsection{Compression test}

The test of compression was carried out at the laboratory by using cubic specimens of dimensions $(100 \times 100 \times 100) \mathrm{mm}^{3}$, the cubic specimens placed in the center of a press (machine type CONTROLS-DIGIMAX with Max load of 5000KN), and so that the loading is carried out perpendicular to the direction of pouring, according to European standard NF IN 12390-3. The results of the compressive strength of the concrete test-tubes reinforced by glass fibers AR are presented at Figure 2 .

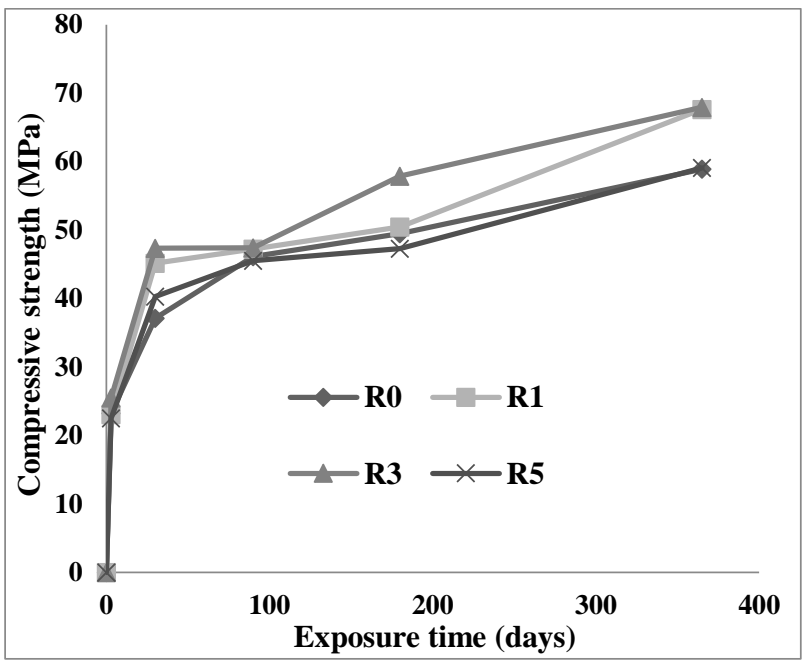

Figure 2. Compressive strength of concrete specimens with different percentages of fibers

According to Figure 2, the compressive strength of the R0 test-tubes, R1, R3 and R5 increases in continuous way until age the 365 days, as well as maximum resistances are equal to $58.90 \mathrm{MPa}, 67.66 \mathrm{MPa}, 67.95 \mathrm{MPa}$ and $59.09 \mathrm{MPa}$ respectively. Which confirms the hydration continues concrete fiber with additions of the silica fume and of the slag under the effect of the wet cure and the formation of calcium silicate hydrates $(\mathrm{C}-\mathrm{S}-\mathrm{H})[13,14]$. That leads to minimize the permeability of the concrete, thus the increase of compressive strength. In addition, as per Figure 2, we notice that the compressive strength of the R3 test-tubes is higher than the other test-tubes; the R0 test-tube presents the lower values of compressive strength. Which explains the positive effect of reinforcement of the concrete by glass fibers on the durability of the concrete immersed in the wet medium. The compressive strength of the test-tubes R0, R1, and R5 are less than value of compressive strength of R3 test-tube by a percentage of $13.32 \%, 0.43 \%, 13.04 \%$ respectively at the 365 days age. These results confirmed that the percentage of fibers to obtain a better compressive strength is between 2 and $4 \%$ according to İskender et al. [9].

\subsection{Flexural test}

The flexural strength of the prismatic test-tubes (70x70x280) $\mathrm{mm}^{3}$ was established in accordance with European standard NF P18-407. The prismatic test pieces are placed in the test machine (CONTROLS type machine with a maximum load of $3000 \mathrm{KN}$ ). The load is applied without shock and continuously to the face perpendicular to the surface of the molding, with a constant speed until the breaking of the test piece. The values of the flexural strength of the concrete test-tubes reinforced by AR glass fibers after 365 days of wet cure are presented in Figure 3 .

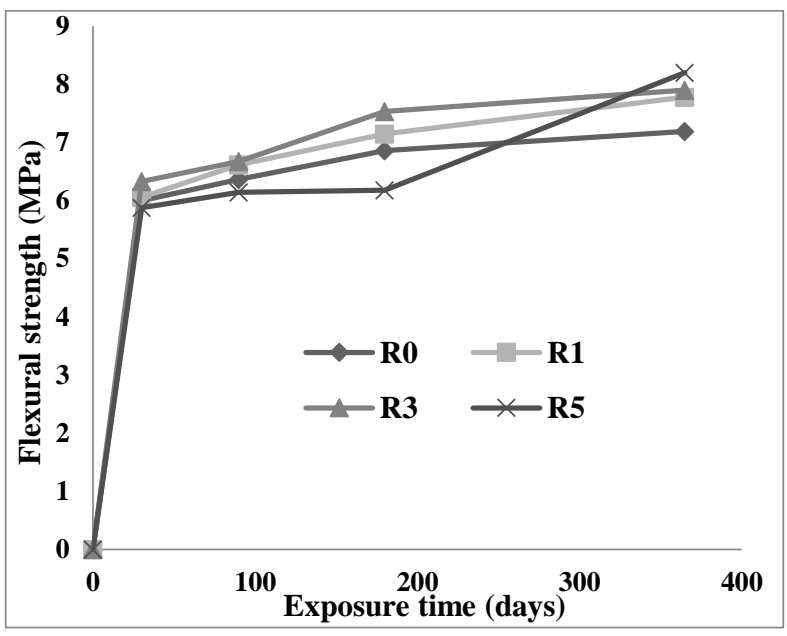

Figure 3. Flexural strength of concrete specimens with different percentages of fibers

According to Figure 3, the flexural strength of the test-tubes $\mathrm{R} 0, \mathrm{R} 1, \mathrm{R} 3$ and R5 increases in continuous way until age the 365 days, as well as maximum resistances are equal to 7.19 $\mathrm{MPa}$, 7.78 $\mathrm{MPa}$, 7.90 $\mathrm{MPa}$ and 8.20 $\mathrm{MPa}$ respectively. These results are confirmed with those found in the test of mechanical resistance to compression. More still, we notice that the flexural strength of the R5 test-tubes is higher than the other test-tubes at the 365 days age. The R0 test-tubes present the lower value of flexural strength. Which explains the positive effect of reinforcement of the concrete by fibers on the mechanical resistance and the durability of the concrete. The flexural strength of the test-tubes R0, R1, and R3 compared to the R5 test-tubes, show regressions of $12.32 \%$, $5.12 \%, 3.66 \%$ respectively at the 365 days age. Consequently, 
the addition of $5 \%$ of glass fibers with a length of $36 \mathrm{~mm}$ improves the flexural strength of concrete [9].

\subsection{Results of mass of test pieces}

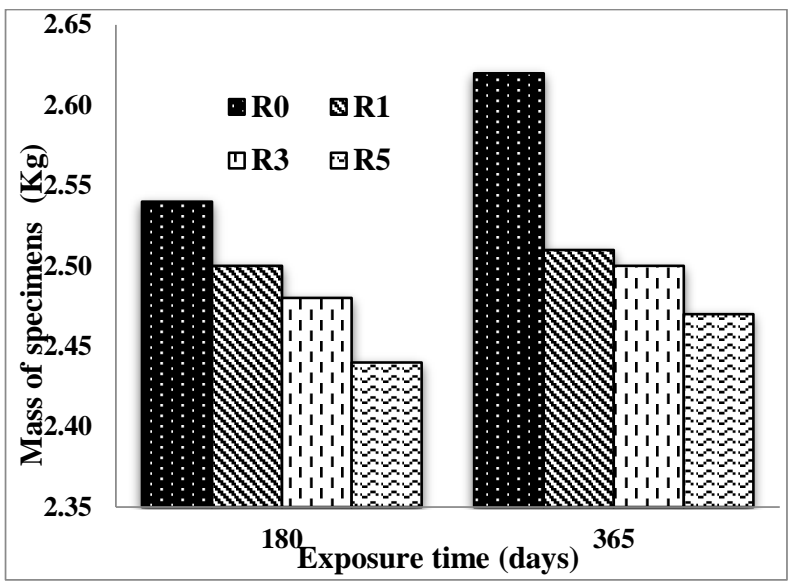

Figure 4. Mass of concrete specimens with different percentages of fibers

This test was carried out at the laboratory by the use of an electric balance. Values of the mass of the concrete test-tubes reinforced by glass fibers AR after 180 and 365 days of wet cure are presented in Figure 4.

Figure 4 shows that the mass of the $\mathrm{R} 0$ test-tubes is higher than the other test-tubes, the R5 test-tube present lower value of flexural strength at the age of 180 and 365 days respectively. The mass of the test-tubes R1, R3, and R5 compared to the R0
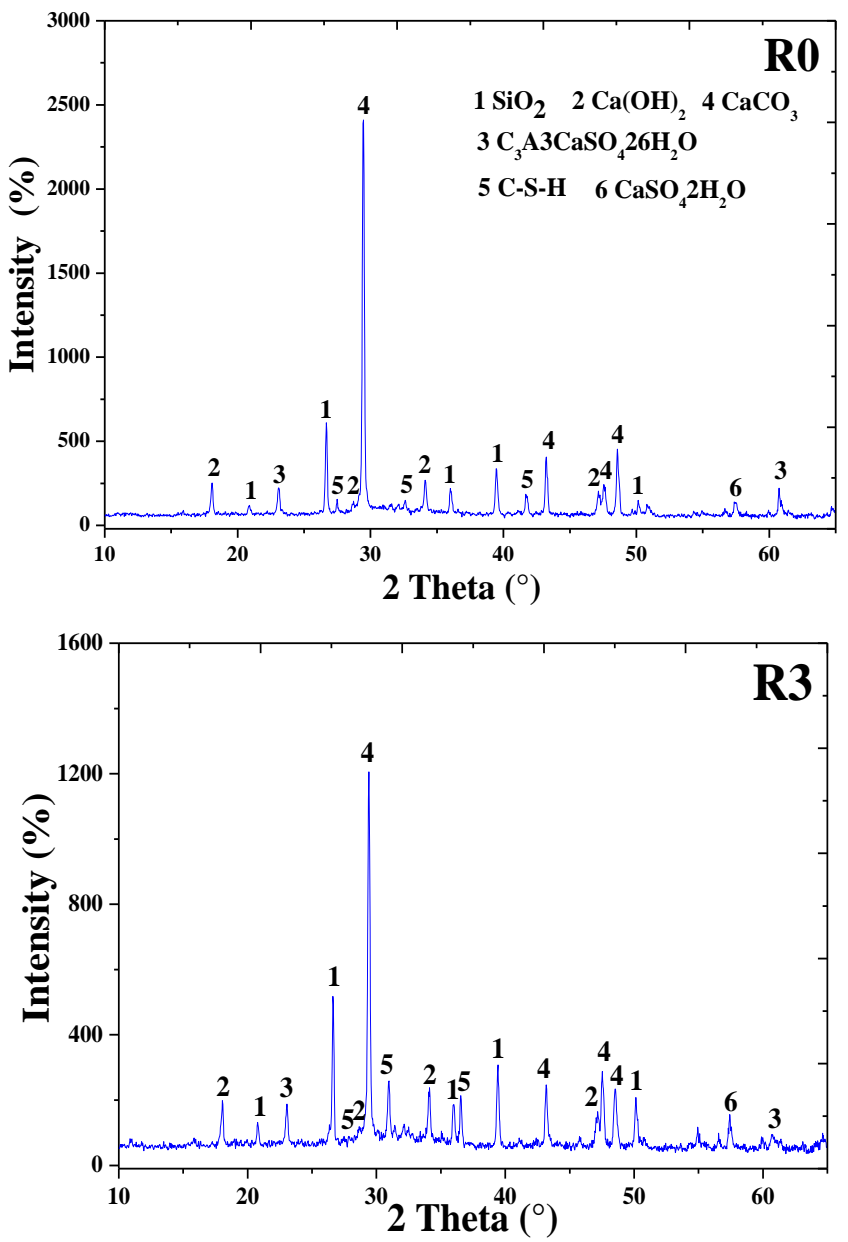

test-tubes, show regressions of $1.58 \%, 2.36 \%, 3.94 \%$ respectively at the 180 days age, and regressions of $4.20 \%$, $4.58 \%, 5.72 \%$ respectively at the 365 days age. Which confirms the continues hydration of concrete fiber with additions of the silica fume and the slag under the effect of the wet cure and the formation of calcium silicate hydrates (C-S$\mathrm{H})$, which minimize the porosity of concrete [13, 14]. More still, the percentage of fibers increases, the porosity of the concrete increases and the mass of the concrete decreases. But this increase in porosity does not have any influence on the mechanical resistance of the concrete fiber test-tubes.

\subsection{Results of the XRD analyses}

The results of the chemical analyses by X-rays diffraction of the surface layers of the concrete fiber test-tubes preserved in a wet medium up to 365 days are presented in Figure 5.

Figure 5 shows that the skin of the four types of the concrete fiber, which contains traces of Ettringite crystalline, gypsum, C-S-H, calcium carbonate, $\mathrm{SiO}_{2}$, of Portlandite to the peaks (2 Theta) $18.13 ; 28.66 ; 33.96$ and 47.14. Several peaks of the type C-S-H detected confirm the hydration continues concrete fiber with additions of the silica fume and slag under the effect of the wet cure. More still, the addition of the rate of $3 \%$ of the silica fume and $20 \%$ of the slag reduced the phenomena of attacks of fibers because of the pozzolanic effect which transforms the portlandite $\mathrm{Ca}(\mathrm{OH})_{2}$ into $\mathrm{C}-\mathrm{S}-\mathrm{H}$ and to decrease the porosity of the concrete fiber. In addition, the $\mathrm{Ca}^{2+}$ ions can be combined with the silica fume to form new calcium silicate hydrates $[13,14]$. These results are in adequacy with those obtained following the preceding tests.
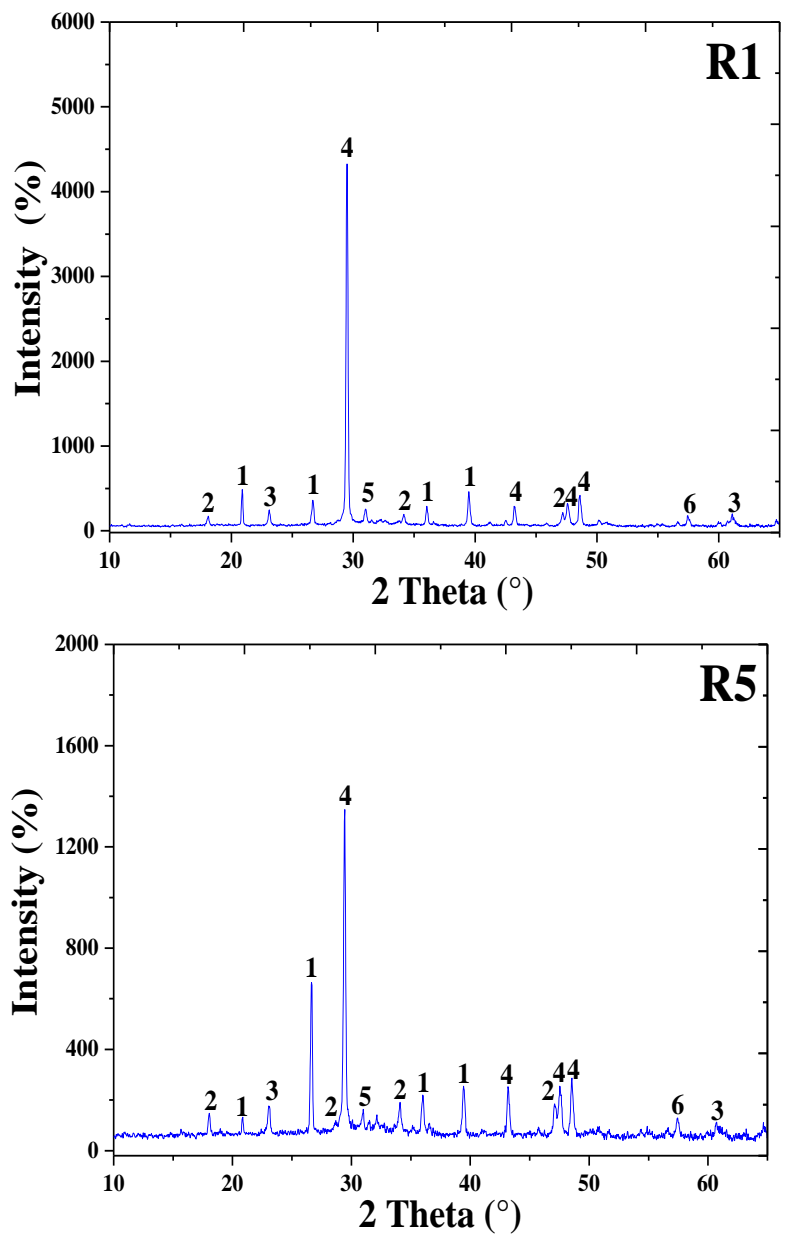

Figure 5. X-ray diffraction analysis of the R0, R1, R3 and R5 specimens conserved in the wet medium 


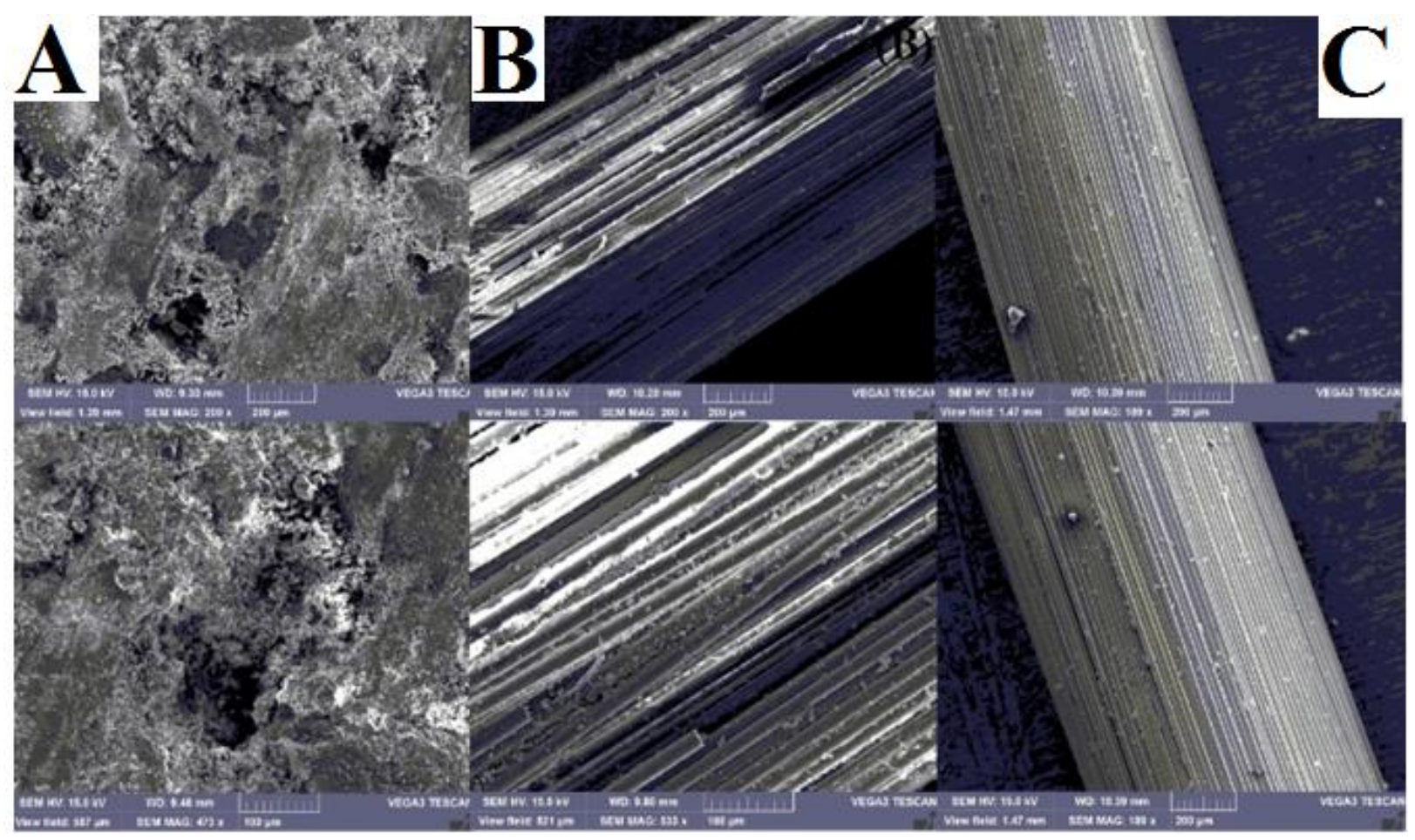

Figure 6. SEM observations: (A) The cementing matrix hydrated (B) AR fibers conserved in the wet environment at 365 days of age (C) AR fibers in a natural state

\subsection{SEM test results}

The observations made under the electron microscope with sweeping are deferred on Figure 6 made up of six photographs (matrix fibers, glass fiber after 365 days duration immersion, fiber in a natural state or witnesses).

The aspect of fibers before incorporation in the matrix is deferred on the Figure 6C. The cementing matrix hydrated after conservation is in a good state as Figure $6 \mathrm{~A}$ shows it. The glass fibers after conservation are presented in the Figure 6B, the damage has been observed on the strands of fibers. It can be justified that the damages observed on the surface of fibers is created during mixing of the concrete and by the effect and contact between the fibers and the gravels (See Figure 7).

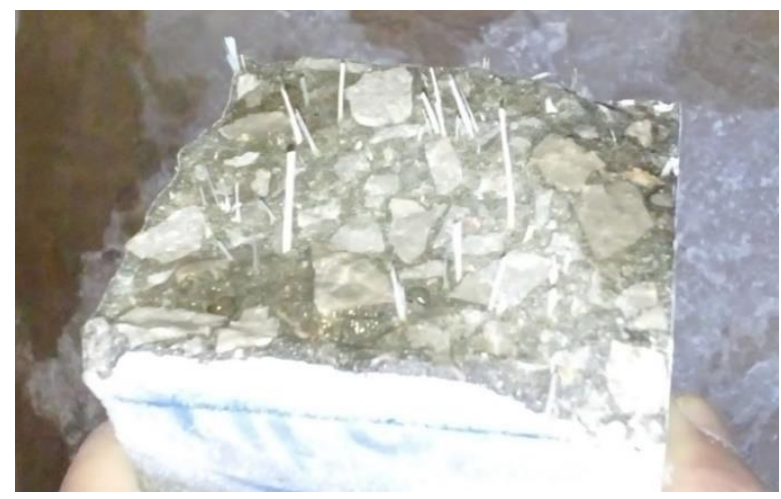

Figure 7. ARHP fibers after conservation of the concrete in a period of 365 days

Furthermore, the SRC cement used in our study has a higher $\mathrm{C}_{3} \mathrm{~S}$ content, which leads to an increase in portlandite $\left(\mathrm{Ca}(\mathrm{OH})_{2}\right)$ after the hydration of the cement [15]. This latest has a negative influence on the durability of the glass fibers. To reduce the negative effect of portlandite; we have replaced a portion of cement with the addition $20 \%$ of slag and $3 \%$ of silica fume. These additions can considerably accelerate the hydration, reduce the content of anhydrous portlandite and $\mathrm{C}_{3} \mathrm{~A}$, and reduce permeability, pore size and connectivity. Which leads to improve the mechanical properties and durability of concrete [16, 17], however, this solution does not give a sufficient protection of the surface of fibers in the environment alkaline. The performance of glass fibers ARHP can improve the mechanical resistance of the concrete at longterm in the wet medium.

\section{CONCLUSION}

We conclude according to this study that the compressive and flexural strength of the concrete fibers test-tubes are higher for a percentage of glass fibers of $3 \%$ except flexural strength at the 365 days age. Percentage of $5 \%$ of the glass fibers influence negatively the mechanical characteristics of the concrete fiber. The use of SRC cement with additions of $3 \%$ of the silica fume and $20 \%$ of the slag can decrease the porosity of the concrete fiber and increase their mechanical resistance. Lastly, the glass fibers ARHP can improve the durability of the concrete at long-term in the wet medium.

\section{REFERENCES}

[1] History of Fiberglass. Technical Report, Latham pool products, behind every pool since, North America. https://www.lathampool.com/, accessed on Jan. 6, 2020.

[2] Bagherpour, S. (2012). Fiber Reinforced Polyester Composites. Polyester, 135-166. https://doi.org/10.5772/48697

[3] Zollo, R.F. (1997). Fiber-reinforced concrete: An overview after 30 years of development. Cement and Concrete Composites, 19(2): 107-122. https://doi.org/10.1016/S0958-9465(96)00046-7 
[4] Abdullah, M.M., Jallo, E.K. (2012). Mechanical properties of glass fiber reinforced concrete. Alrafidain Engineering, 20(5): 128-135.

[5] Naaman, A.E. (2007). High performance fiber reinforced cement composites: Classification and applications. CBM-CI International Workshop, Karachi, Pakistan, pp. 389-401.

[6] Enfedaque, A., Paradela, L.S., Sánchez-Gálve, V. (2012). An alternative methodology to predict aging effects on the mechanical properties of glass fiber reinforced cements (GRC). Construction and Building Materials, 27(1):

425-431. https://doi.org/10.1016/j.conbuildmat.2011.07.025

[7] Lipatov, Y.V., Gutnikov, S.I., Manylov, M.S., Lazoryak, B.I. (2012). Effect of $\mathrm{ZrO}_{2}$ on the alkali resistance and mechanical properties of basalt fibers. Inorganic Materials, 48(7):

$751-756$ https://doi.org/10.1134/S0020168512060106

[8] Gornale, A., Quadri, S.I., Quadri, S.M., Ali, S.M.A., Hussaini, S.S. (2012). Strength aspects of glass fiber reinforced concrete. International Journal of Scientific and Engineering Research, 3(7): 1-5.

[9] İskender, M., Karasu, B. (2018). Glass fibre reinforced concrete. El-Cezerî Journal of Science and Engineering, 5(1): 136-162. https://doi.org/10.31202/ecjse.371950

[10] Bartos, P.J.M. (2017). Glass fiber reinforced concrete. IOP Conference Series: Materials Science and Engineering, 246: 13-16.

[11] Butler, M., Mechtcherine, V., Hempel, S. (2010). Durability of textile reinforced concrete made with AR glass fiber: Effect of the matrix composition. Materials and Structures, 43: 1351-1368. https://doi.org/10.1617/s11527-010-9586-8

[12] Arabi, N. (2011). Influence of curing conditions on durability of alkali-resistant glass fibers in cement matrix. Bulletin Material Science, 34(4): 775-783. https://doi.org/10.1007/s12034-011-0194-1

[13] Arabi, N., Molez, L., Rangeard, D. (2018). Durability of alkali-resistant glass fibers reinforced cement composite: microstructural observations of degradation. Periodica Polytechnic Civil Engineering, pp. 10631. https://doi.org/10.3311/PPci.10631

[14] Peled, A., Jones, J., Shah, S.P. (2005). Effect of matrix modification on durability of glass fiber reinforced cement composites. Materials and Structures, 38: 163171. https://doi.org/10.1007/BF02 479341

[15] Divet, L. (2001). Les réactions sulfatiques internes au béton: contribution à l'étude des mécanismes de la formation différée de l'ettringite. Central laboratory of bridges and roadways, Paris.

[16] Gupta, S. (2016). Effect of content and fineness of slag as high volume cement replacement on strength and durability of ultra-high performance mortar. Journal of Building Materials and Structures, 3(2): 43-54. http://doi.org/10.5281/zenodo.242626

[17] Moffatt, E.G., Thomas, M.D.A. (2018). Performance of 25-year-old silica fume and fly ash light weight concrete blocks in a harsh marine environment. Cement and Concrete Research, 113: 65-73. https://doi.org/10.1016/j.cemconres.2018.07.004 